\title{
Screening for Veteran Status in the Primary Care Setting
}

\author{
Dean A. Seebusen, $M D, M P H$
}

Almost 24 million Americans are military veterans. ${ }^{1}$ The size of this population and the fact that veterans are at increased risk for a wide variety of health complications make the care of veterans an important component of primary care. The large demand placed on the National Guard and Reserves from current conflicts has resulted in a very large percentage of veterans' care being delivered in the civilian sector. The article by Hinojosa et $\mathrm{al}^{2}$ in this issue of the fournal highlights the need for identification of this subpopulation and describes an approach to their care.

Reintegration of the veteran into their family and their community is a period of considerable risk. This can be a very tumultuous and stressful time for veterans. This is when a veteran has to adjust to life outside a combat zone, interacting with civilians regularly and renegotiating their place within their family. Rates of mood disturbance, substance abuse, and marital strife are higher during this time. Some veterans will have encounters with the law or become violent or even suicidal during the reintegration period. Reintegration varies in length for each individual, but eventually the primary needs of the veteran will shift and their chronic health issues will become more pressing. Chronic health care needs will include both physical and mental conditions and may last indefinitely. CO.

From the Evans Army Community Hospital, Fort Carson,

Funding: none.

Conflict of interest: none declared.

Disclaimer: The opinions or assertions contained herein are the private views of the author and are not to be construed as official or as reflecting the views of the Department of Defense, US Army Medical Corps, or the United States at large.

Corresponding author: Dean A. Seehusen, MD, MPH, Evans Army Community Hospital, 1650 Cochrane Circle, Fort Carson, CO 80913 (E-mail: dseehusen@msn.com).

See Related Article on Page 770.
Justifiably, Hinojosa et $\mathrm{al}^{2}$ describe the need for screening as the first step in getting veterans the care they deserve. Institutionalized screening, such as that suggested by the authors, clearly is needed to indentify veterans and their problems. Which patients are veterans is not obvious. Given the makeup of today's deploying forces, veterans come from all walks of life. Veterans are present in all adult age groups and, increasingly, many veterans are women.

The wounds of war are not always visible. The conditions that have often been described as the "signature injuries" of the current conflicts-mild traumatic brain injury and posttraumatic stress disorder (PTSD) - typically go unnoticed unless they are specifically sought out. Even in settings like the Veteran's Health Administration and the Department of Defense medical facilities, these conditions can be easily missed.

If standard criteria for screening interventions are applied, screening for veteran status and subsequently for mild traumatic brain injury and PTSD stands up well. Veterans make up more than $5 \%$ of the US population, and these conditions are common among the group. Screening is inexpensive and noninvasive. The screening tools are reasonably sensitive and false-positives do not lead to onerous or dangerous follow-up testing.

The United States Army has instituted a program known as RESPECT-Mil to actively screen all service members whenever they received medical care. The "Re-engineering Systems of the Primary Care Treatment (of Depression and PTSD) in the Military" program was designed in conjunction with researchers from the academic community. Each soldier answers 6 yes/no questions on an initial screening tool. Positive answers result in further screening. The goals of the program include earlier identification of conditions and reducing stigma. ${ }^{3}$

Hinojosa et $\mathrm{al}^{2}$ go on to suggest ways that providers can help veterans achieve optimal health 
outcomes. It should not be a surprise that, whether newly returned from combat or back for decades, veterans benefit from the same key components of care as any other patient. Veterans will achieve the best outcomes from a medical system that is characterized by continuity of care, timely access, and comprehensiveness. All patients benefit from having a physician whom they trust, who intimately knows their medical conditions, and who can successfully integrate a multidisciplinary team. These are among the founding tenets of family medicine and are the key components of the concept of the patient-centered medical home. Veterans require a medical home not because they are veterans, but because they require quality medical care, the same as any other patient.

\section{References}

1. Quinlan JD, Gauron MR, Deschere BR, Stephens MB. Care of the returning veteran. Am Fam Physician 2010;82:43-9.

2. Hinojosa R, Sberna Hinojosa M, Nelson K, Nelson D. Veteran family reintegration, primary care needs, and the benefit of the patient-centered medical home model. J Am Board Fam Med 2010;23: $770-4$.

3. United States Army Public Affairs. Army announces new health program: RESPECT-Mil. Available at: http://www.pdhealth.mil/downloads/RESPECT-Mil_ Media_Release.pdf. Accessed 6 August 2010. 